\title{
COMMUNICATIONS
}

\section{STERILE DROPS AND LOTIONS IN OPHTHALMIC PRACTICE*}

\author{
BY \\ FREDERICK RIDLEY \\ London
}

THE carriage of pathogenic bacteria to eyes through the agency of drops has presented a serious problem for several decades and this problem has not, hitherto, been effectively solved. Screw-cap bottles and the use of a preservative in all drops were recommended by a committee of the High Holborn Branch of Moorfields in 19541. A Dispensary and Sterilization Committee serving the joint hospital was set up in $1955^{2}$. The author was in the best position to devise and put into operation the practical requirements of such a scheme, and the High Holborn Branch of the Hospital was used throughout to test various methods of control. The material to be presented has been divided into that of general interest in large type and in smaller type the practical details, chiefly of interest to the pharmacist.

\section{SCOPE OF THE PROBLEM}

It was demonstrated that practically all the drops in use in the hospital, including many bottles that had not yet been opened, were infected. Secondly, it was shown that Ps. pyocyanea in particular was liable to infect a wide range of drops and ointments, and that the antibiotics, in strengths commonly used in ophthalmology, offered no effective protection. Care in the use of drops-seeing that the eye being treated is not touched by the dropper and that the neck of the bottle is not touched either in removing or inserting the dropper, and so on-is not effective. The drops must be self-sterilizing. As a corollary, if it is necessary to use unprotected drops, then they must be put up sterile in a sterile sealed container and used only once and with full aseptic precautions.

\section{Protection of Drops}

The introduction of a preservative into drops has been proposed and indeed used for many years. The national formulary follows the British Pharmaceutical Codex in recommending Liquor pro Guttis $(0.023$ per cent. methyl hydroxy-

* Received for publication March 4, 1958.

1. Messrs. C. H. Greer, H. E. Hobbs, and J. G. Milner.

2. Messrs. N. Ashton (Chairman), A. J. B. Goldsmith, A. Lister, E. S. Perkins, F. Ridley, H. Ridley. 41 641 
benzoate and 0.011 per cent. propyl hydroxybenzoate) for all drops in aqueous solution. Klein, Millwood, and Walther (1954) have drawn attention to the fact that this concentration is at least three times too little to be effective against Ps. pyocyanea. Phenylmercuric nitrate in a concentration of 0.004 per cent. is effective against Ps. pyocyanea, however, even in fluorescein solution, and is relatively non-poisonous and innocuous in this concentration. It is probable that there are other substances as effective as these. The objective was to devise and put into operation a practicable scheme securing safe drops and lotions throughout the hospital: 0.1 per cent. methyl hydroxybenzoate (M.H.B.) and 0.004 per cent. phenylmercuric nitrate (P.M.N.) had been well tried and had proved effective. The objection to the use of M.H.B. in all drops is that in this concentration ( 0.1 per cent.) it is more irritating than P.M.N. 0.004 per cent., and that in certain solutions, notably fluorescein and eserine (Klein and others, 1954), it is less efficacious against $P$ s. pyocyanea.

Sensitization.-Using P.M.N. 0.004 per cent. or M.H.B. 0.1 per cent. to cover the whole range of aqueous drops, very few cases of dermatitis medicamentosa attributable to the preservative used were seen in 3 years' practice in the hospital. Those cases which did occur were seen in the Out-Patient Department, where drops protected by P.M.N. have been used for a long period of time, and in every case the reaction was slight and the patient was made comfortable by changing either the drops or the preservative used in the drops.

Choice of Protective Solutions.-P.M.N. and M.H.B. in these concentrations, both as reported by Klein and as tested in Prof. Ashton's laboratory, proved effective against a wide range of bacteria tested, including Ps. pyocyanea, Streptococcus pyogenes, and Staphylococcus aureus at room temperature, in conjunction with the drugs commonly used and in normal clinical concentrations, in 3 hours.

Solutions of P.M.N. and M.H.B. are made up in distilled water, and the solution is used as a diluent in normal dispensary practice. It is convenient to dissolve the P.M.N. by adding the powder to distilled water to produce a 0.01 per cent solution and autoclaving. This is further diluted as required.

P.M.N. gives a faint cloudy precipitate if added to solutions containing free chloride or bromide ions, since the chloride and bromide, as opposed to the nitrate, are relatively insoluble. It has been argued that this relatively insoluble chloride is useless, but experiments conducted by Prof. Ashton show that this is not so and that such solutions are fully effective. This is analogous to silver nitrate precipitated as chloride: the relatively insoluble chloride will kill pathogenic staphylococci at a dilution of 0.1 per cent. in 10 per cent. serum-saline, and inhibits down to 0.004 per cent. (F. Ridley, 1931).

Antibiotics are said to be unstable when mixed with heavy metal salts in solution, but the mercury atom is part of the "phenylmercuric" radicle in P.M.N. and is probably harmless in this context; Klein and Millwood (1955) have shown that penicillin solution protected with 0.05 per cent. P.M.N. is stable for several weeks.

Cortisone acetate and hydrocortisone are protected with $\mathbf{0} \cdot 1$ per cent. benzyl alcohol as supplied by the makers. This concentration is irritating and unsuitable for use in ophthalmology and the makers' preparation has been diluted to the concentrations used in the hospital (cortisone acetate $(0.25$ per cent.), hydrocortisone $(0.125$ per cent)) by the addition of M.H.B. $0 \cdot 1$ per cent. 
TABLE

\section{PROTECTION OF DROPS}

\begin{tabular}{l|l}
\hline $\begin{array}{l}\text { Methyl Hydroxybenzoate 0.1 per cent. } \\
\text { (M.H.B.) }\end{array}$ & $\begin{array}{l}\text { Adrenalin, Amethocaine, Antazoline Compound, } \\
\text { Atropine Methylnitrate, Chloramphenicol, Cocaine } \\
\text { Hydrochlor, Cortisone, Ephedrine, Ethylmorphine } \\
\text { (Dionine), Gelatin Eye Drops, Homatropine, Homatro- } \\
\text { pine and Cocaine, Hydrocortisone, Hyoscine, Laches- } \\
\text { ine, Liquocaine, Neomycin Sulph., Penicillin, Potassium } \\
\text { Iodide, Sodium Iodide, Streptomycin, Sulphacetamide, } \\
\text { Zinc Sulphate, Zinc Sulphate and Adrenalin. }\end{array}$ \\
\hline $\begin{array}{l}\text { Phenylmercuric Nitrate 0.004 per cent. } \\
\text { (P.M.N.) }\end{array}$ & $\begin{array}{l}\text { Atropine, Copper Sulphate, Duboisine, Eserine, } \\
\text { Fluorescein, Glycerine, Methylcellulose, Pilocarpine, } \\
\text { Ringer-Saline, Sulphacetamide and Zinc. }\end{array}$ \\
$\begin{array}{c}\text { Phenylephrine Ophthalmic Solution } 10 \\
\text { per cent. (Boots) and Prostigmin } \\
\text { per cent. (Roche Products Ltd.) }\end{array}$ & Used as issued. \\
\hline
\end{tabular}

\section{Protection of Oils And Ointments}

There is no effective preservative which can be used to protect oils and ointments, and the same danger exists for them as for aqueous drops. Indeed, Ps. pyocyanea has been isolated from ointment on several occasions. It is proposed to eliminate the use of oily drops entirely in the practice of Moorfields Hospital, oils being replaced by ointments. Ointments are dispensed only in sterile tubes and, in practice, a little is expressed on to a sterile glass rod and by this means applied to the eye. This safeguard is unnecessary where the tube is dispensed for an individual patient.

\section{CONTAINERS}

\section{BOTTLES}

The orthodox Chalk's bottle has been abandoned entirely, since the unit cannot be sterilized by heat as the massive glass base is liable to crack. As normally constructed, the dropper is ground into the neck of the bottle and is therefore an individual fit, so that the whole unit has to be separately washed and the dropper identified with its own bottle, thus making any semi-automatic washing, drying, and sterilizing impossible. The rubber diaphragm commonly used is wasteful of time in assembly and has a short life. In the commonly available samples Chalk's bottles have no hood attached to the dropper covering the neck of the bottle, and the neck therefore collects dust and is contaminated by the drops themselves however careful one may be. On returning the dropper to Chalk's bottle it is very common for this dirt to be carried by the dropper from the edge of the neck into the drops. Over several months an extensive series of cultures of the contents and of the neck of Chalk's bottles was taken; the results did not compare with the standard obtained with screw-cap bottles. 
Screw-cap bottles, preferably square*, which are provided with a plastic collar and a rubber unit carrying the glass dropper and rubber teat, have been found effective and convenient in use. The glass dropper should have a round ball-end, other dropper ends not being so safe or effective in use. Screw-cap bottles have the merit that the drops are sealed so that evaporation is eliminated, the neck of the bottle is fully protected, the parts are interchangeable, and the bottles inexpensive. The whole unit or its parts can be autoclaved or sterilized by dry heat. Since the parts are interchangeable the bottles can be dismantled, washed, autoclaved, and re-assembled very simply. The square bottle is the more convenient in use since it is less easily upset. These bottles in the standard quarter-ounce and half-ounce sizes have covered all requirements.

Method of Preparing Bottles.-Dirty bottles returned to the dispensary are first stripped to their component parts and washed in running water-an under-water jet is a convenient device. The labels are soaked off and may be collected in a suitable label trap built into the sink; it is essential that labels used should soak off in this way. The washed components are inspected as they are passed into perforated trays (Fig. 1), in which they are then placed in a standard sterilizer containing a non-foaming detergent such as Loral. After being boiled the units, still in their trays, are lifted out and drained. They are turned over and immersed in distilled water in a sink and so refilled. In this way traces of detergent, etc. are removed and the bottles, wetted with distilled water, are now placed in the same trays in an oven in which they are dried. This oven may be a domestic gas oven set just above $100^{\circ} \mathrm{C}$. The components are re-assembled but the cap is not screwed down. The bottles are packed into half-biscuit tins (Fig. 2), $†$ each holding fifty or sixty bottles. The lid is put on the tin, and the whole tinful of bottles is sterilized in a hot air sterilizer and stored for future use.

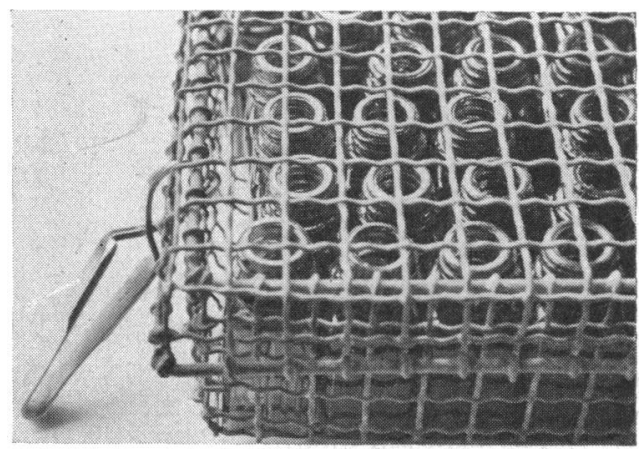

FIG. 1.-Wire tray filled with bottles for sterilizing in boiling water.

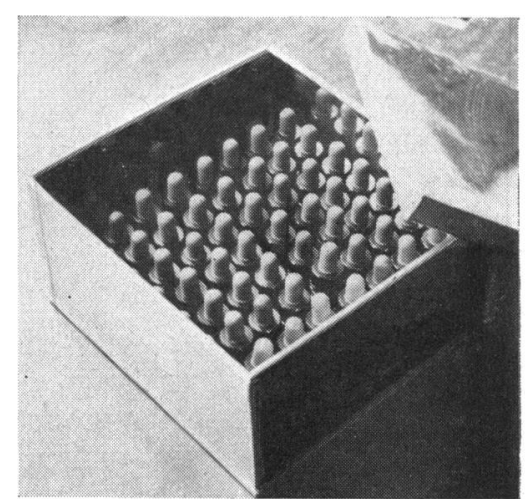

Frg. 2.-Bottles packed into tin for sterilizing in hot air.

Filling the Bottles.-A semi-automatic unit $\ddagger$ is used (Fig. 3, opposite). Compressed air is passed through a cotton-wool filter into the blood bottle containing the drops that are being dispensed. This compressed air may be derived from a simple hand-bellows or foot-pump, but we have found it more convenient to use a foot-pump compressing air in a two gallon tin provided with a safety valve, which may be the release valve of a

* These screw-cap bottles are supplied by Maw, Son, and Sons, Barnet.
+ Available from Huntley, Bourne, and Stevens Ltd., Reading, Berks.

$\ddagger$ The unit illustrated is available from Messrs. Matburn, 25, Red Lion Street, London, W.C.1. 


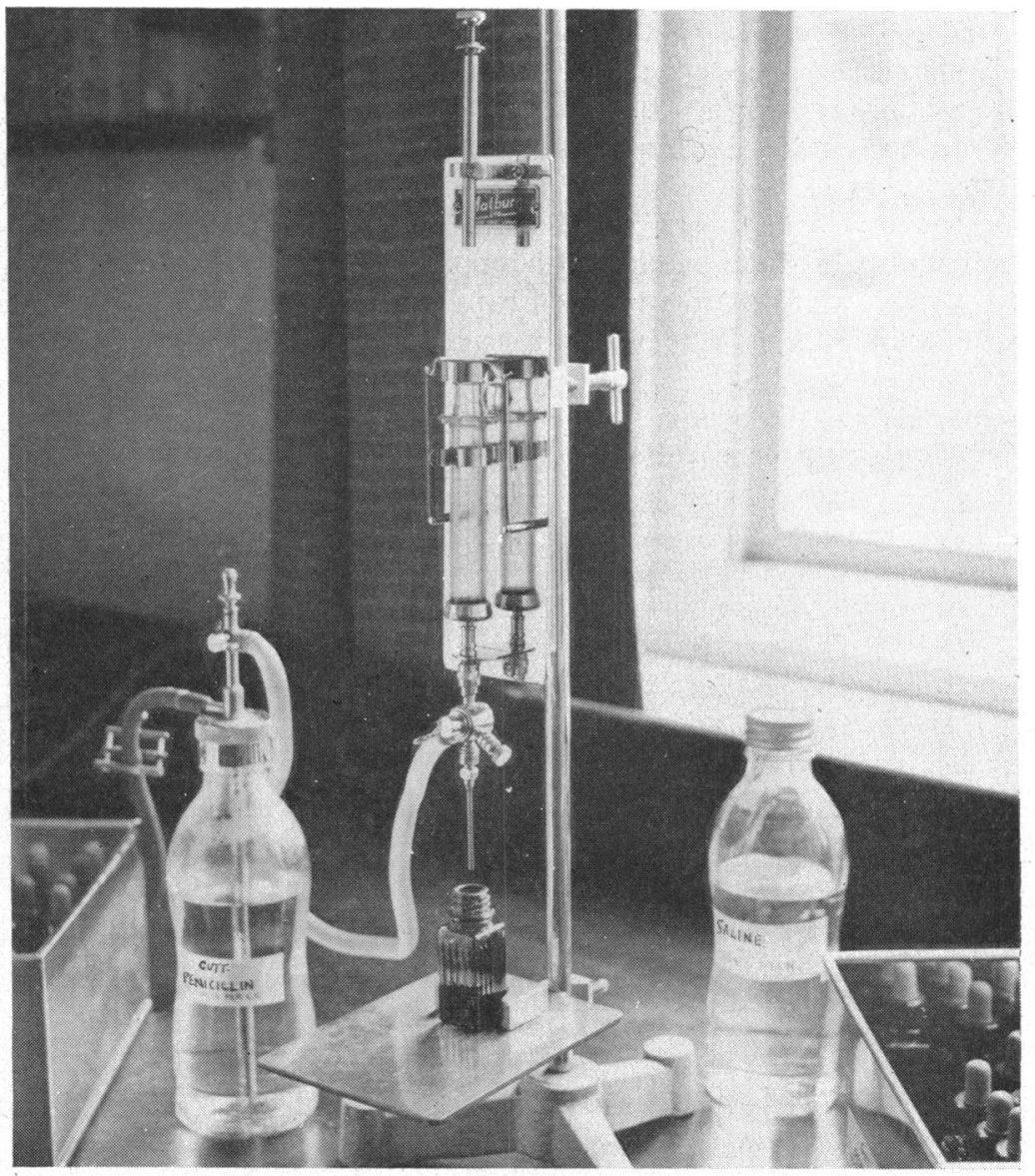

FIG. 3.-Unit assembled for filling bottles.

domestic pressure cooker set for $10 \mathrm{lb}$. per square inch. Up to an hour's filling of bottles may be undertaken without re-pumping. The filling unit, including the stand, syringe, clamps, etc., but excluding the compressed air reservoir, can be autoclaved without dismantling it. It is desirable to lubricate the plunger of the syringe with silicone grease. Two or three hundred bottles an hour can be filled under sterile conditions and each bottle will receive a fixed quantity of solution. The solutions themselves are easily handled in standard blood bottles as illustrated, and a new bottle can be attached without difficulty. When it is desired to change over from one drug to another, a bottle of protected distilled water is attached and the whole equipment pumped through with several ounces of fluid. A table with localizing pegs holds the bottle in the centred position to receive the jet of fluid. The bottles so filled are screwed down and packed into a tin box which is sealed and labelled, with a corresponding label put inside. The inside of the bottles is thus sterile but the outside is not, and thus the contents are protected. These tins each containing fifty filled bottles are stored ready for individual labelling. 


\section{LABELLING}

Labels should be of suitable printed paper, backed with gum which may be either tragacanth or dextrin. It is essential that they should soak off in hot water. Where drop-bottles are used repeatedly as in the clinic, theatre, or wards, unprotected labels tend to become stained and unsightly. This can be avoided if the labels are painted over with a suitable varnish* which gives a hard clear glaze and is not stained by fluorescein or other coloured drops. It can be wiped clean with a wet swab. Labels so varnished can be boiled off easily. Writing should be either in indian ink or in heavy black pencil; ordinary ink runs.

Colour of Labels.-The International Federation of Ophthalmological Societies (1954) made the following recommendations:

(a) Red: Drugs that in certain circumstances can be dangerous, e.g. mydriatics.

(b) Orange: Drugs to be used with caution, e.g. miotics, priscol, adrenalin, antibiotics, etc.

(c) Green: Drugs without danger, e.g. colloidal silver preparations, zinc sulphate, mild antiseptics, antistine-privine, etc.

(d) Red with Green Bands: Anaesthetics.

It was felt, however, that drugs should be identified not only as to their potential danger but also by their essential ophthalmological properties, and with this in view the following modification has been adopted (Fig. 4 (a), opposite):

(a) Red: Mydriatics

Adrenalin, atropine, atropine methylnitrate, duboisine, ethylmorphine, homatropine hydro-bromide, homatropine and cocaine, hyoscine, lachesine.

(b) Blue: Miotics

Di-isopropylfluorophosphonate, eserine, pilocarpine, prostigmin.

(c) Orange: Antibiotics and Chemotherapeutic Substances

Chloramphenicol, neomycin sulphate, penicillin, streptomycin, sulphacetamide, sulphacetamide and zinc.

(d) Red with Green Bands: Anaesthetics

Amethocaine, cocaine, lignocaine.

(e) White: All Other Substances used as Drops

e.g. antazoline compound, artificial tears, copper sulphate, cortisone, ephedrine, fluorescein, gelatin, glycerine, hydrocortisone, methylcellulose, ravolin, potassium iodide, Ringer-saline, zinc sulphate, zinc sulphate and adrenalin.

\section{Examples of Labels Used}

(a) Individual Patients.-The label illustrated, printed in the appropriate colours on white paper, has been adopted for universal use (Fig. $4(b)$, opposite). It measures $3^{\prime \prime} \times 1^{\prime \prime}$ and, provided that it is attached at the left hand edge of a clear panel in any of the standard drop bottles ( $\frac{1}{4}$-ounce or $\frac{1}{2}$-ounce, square or hexagonal types), two or three clear panels will have unprinted paper over them for writing upon. The printed paper lies over the corrugated panels of glass. For out-patients it is necessary to fill in the appropriate number opposite "both eyes", "right eye", or "left eye", to indicate the number of times daily the drop is to be used (Fig. 5). The patient has a clear instruction, the law is complied with, and one can see at a glance what kind of drug has been dispensed.

* Bostik No. 5293. Suitable thinners to use with this varnish are supplied by the makers, BB Chemical Co., Ltd., Ulverscroft Road, Leicester. 


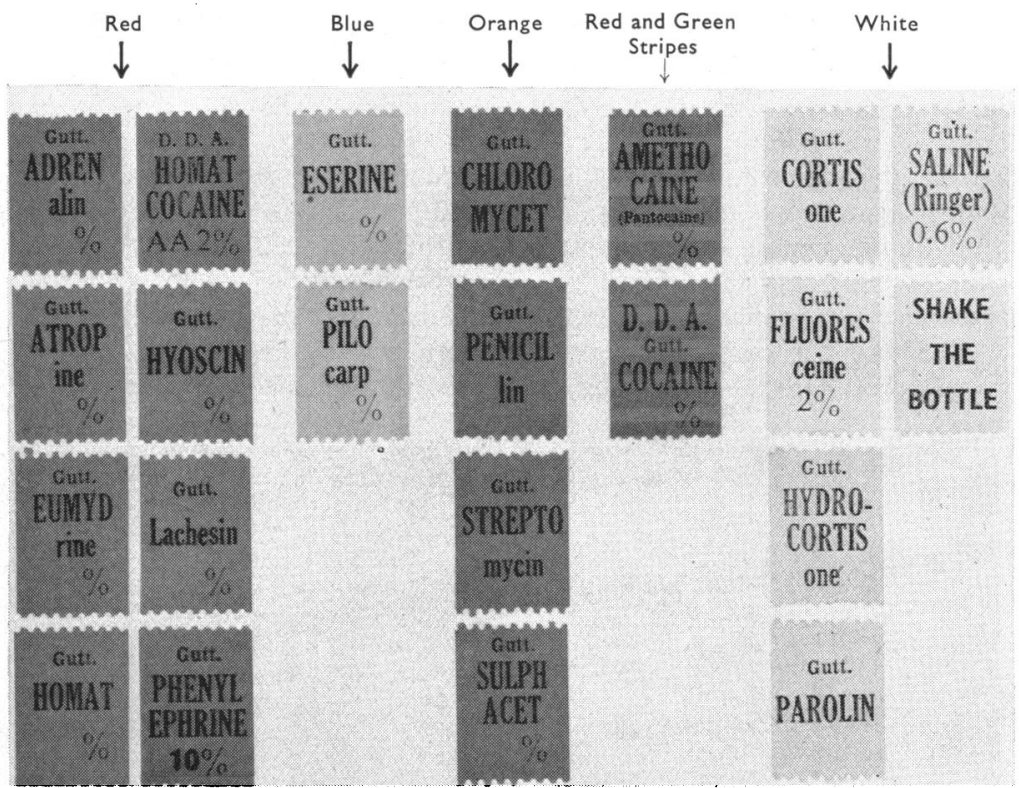

Fig. 4 (a).-Examples of coloured labels for particular drops to be added to the universal label for hospital use.

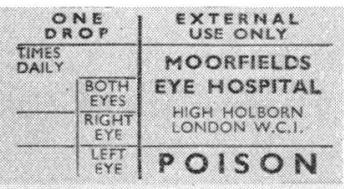

Fig. 4 (b).-Universal label to be printed in four colours for distinguishing various types of drops.

For in-patient use it is necessary to add to this the name of the ward, the name of the patient, and the kind of drug. As a rule the ward can be codified (e.g. Floor 1, 2,3 or Ward A, B, C) and the name of the drug can be abbreviated. An entire panel remains for the patient's name if coding is used for the ward and the drug. Typical labels for in-patient use are illustrated in Fig. 5.

Fig. 5.-Labelled bottles stored in

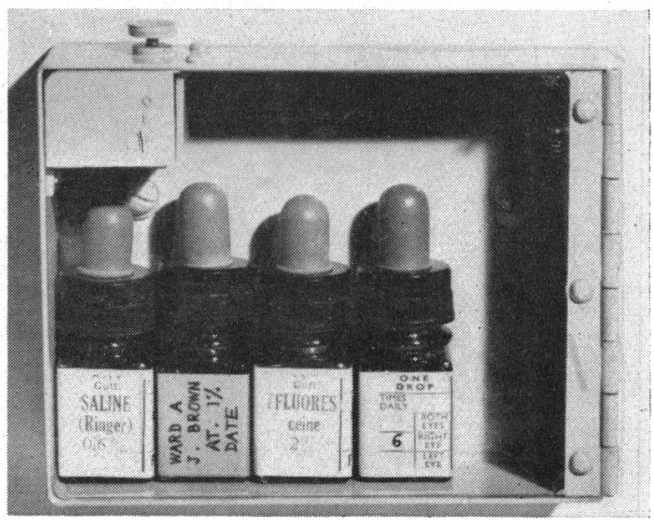
special locked cupboard for ward use. 
(b) Wards and Out-Patients Clinics.-Where drops have to be used in the OutPatients Department, Casualty Ward, and to a limited extent in the General Wards, it is necessary to use a label carrying the name of the drug. These stick-on labels (Fig. 4a) correspond with the colour scheme adopted, and present the name of the drug and its percentage clearly on one panel so that one is not required to read round the bottle which can be dangerous (for instance, amethocaine and cocaine have been confused when not printed fully on one panel). Other essential information is printed on the universal label. For convenience in printing, occasional liberties have been taken with spelling and customary abbreviations have been used. The labels may be printed in perforated rolls of 500. A device for carrying twenty .or more such rolls, presenting them to the operator and keeping the labels dry and clean, is used in the dispensary (Fig. 6)*.

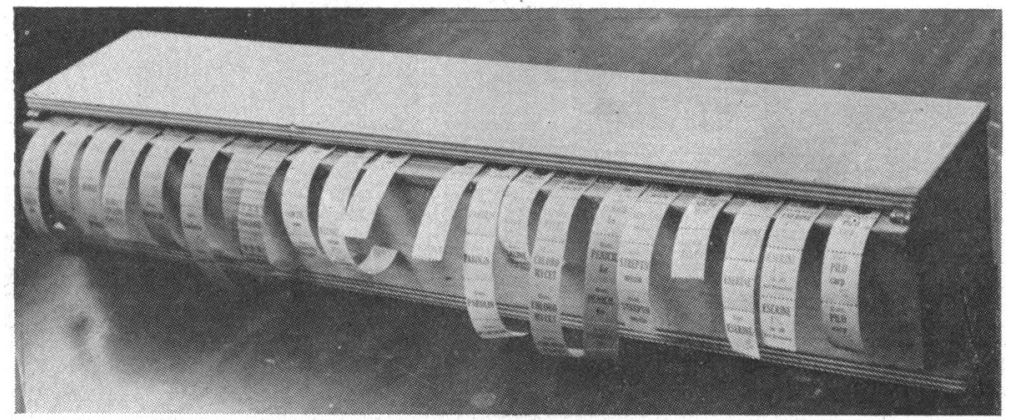

FIG. 6.-Container for dispensing rolls of coloured labels.

Special Arrangements for Handling Drops

In the Out-Patients Department and Casualty Ward an unnecessarily wide range of drops, both as to kind and strength, tends to accumulate. By common consent of the staff, the number of drops routinely set out at each desk has been reduced to a minimum.

Out-Patients Department.-Five kinds of drops (Fluorescein 2 per cent., RingerSaline 0.6 per cent., Eserine 0.25 per cent., Homatropine and Cocaine a.a. 2 per cent., and Cocaine 2 per cent.) are set out in perspex racks (Fig. 7).

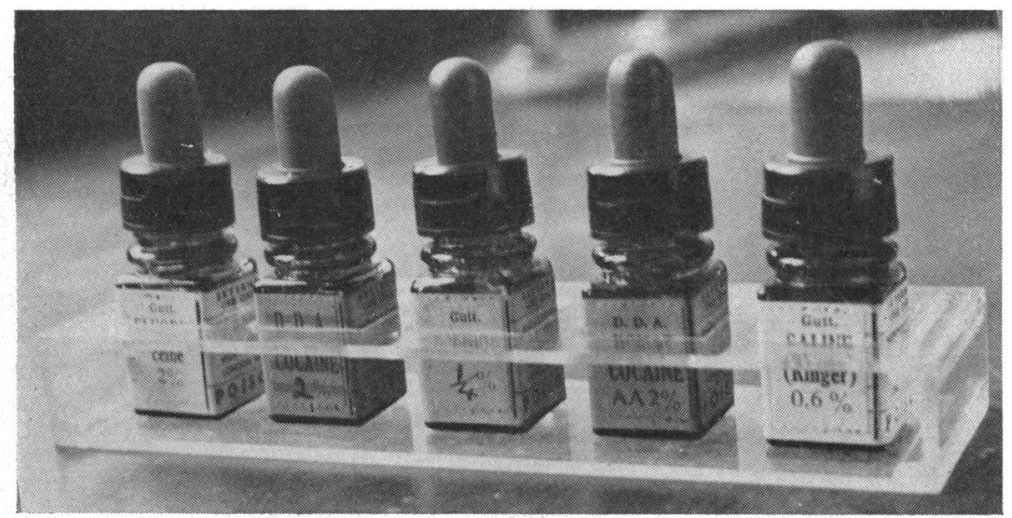

Fig. 7.-Perspex rack for carrying labelled bottles for use in the Out-patients Department.

* M. Harland \& Son Ltd., 12, Norfolk Street, W.C.2. 
In addition, the surgeon nominates whatever drops he wishes to have available for his unit, and these are put out separately on his desk. Any drop may be obtained on request from the dispensary. Alongside the perspex rack of bottles is placed a quantity of glass rods and glass pipettes with rubber teats which have been dry sterilized.

Casualty Ward.-A restricted list of drops is normally set out, and this list is modified from time to time. Homatropine 1 per cent., Atropine 0.5 per cent., Pilocarpine 2 per cent., and Eserine 0.5 per cent. are also available for issue to out-patients at any time. For staining the cornea, a sterile glass rod dipped in Fluorescein 2 per cent. is used, and saline is delivered with sterile pipette. It is unsafe to use the dropper from the drop bottle in infected cases, since experiment has shown that the dropper almost invariably becomes contaminated and the preservative is not effective within some 3 hours.

The Wards.-Cross-infection brought about by the use of the same drop-bottle from case to case in the wards has been established often enough for it to be certain that individual drops must be provided for in-patients.

Medico-legal Aspects of the Problem.-It is the current ruling of the Home Office and of the Ministry of Health that Schedule 1 poisons for adult patients need not be kept under lock and key in the ward if they are dispensed for an individual patient. If a small cupboard for each patient's drops is provided it need only have a simple catch, but if it is thought desirable a lock may be fitted.

Drop Bottles for Individual In-Patients.-The drops cupboard illustrated (Fig. 5)* was designed for this purpose. The body is of brass sheet. The lock is operated by two separate actions $((a)$ the Perspex door is pressed back, $(b)$ the button, top left, is depressed) and the door flies open. The cabinet locks automatically when the door is closed. No part of the cupboard or lock can rust. The labels can be read through the Perspex door. The bottles are protected from dust, and the cupboard is easily cleaned and attractive in appearance. The whole unit can be taken down and washed with a detergent, or if necessary sterilized in P.M.N. 0.01 per cent. Dettol or carbolic preparations destroy perspex and should never be used.

\section{Operating Theatre}

Drops at Operation.-Formerly several sterile Chalk's bottles containing unprotected drops were kept in a sterile container provided with a lid. Bacteriological investigation showed that both the drops and the outsides of the bottles became infected very quickly. This method was replaced by the following theatre procedure:

Standard screw-cap bottles, from which the dropper has been removed, containing protected drops are available. Several dry heat-sterilized droppers are put out on the surgeon's trolley and when drops are required a non-sterile nurse unscrews the cap and holds the bottle conveniently for the operator who withdraws the drops required with a 
sterile pipette and places the pipette on one side after use. In this way it is almost impossible to contaminate the drops within the bottle. This method has proved entirely satisfactory.

Pre-Operative Drops.-The ward sister is provided with the drops used for the preparation of cases for operation and the appropriate drops are issued to the nurse preparing each case. After use the drop-bottles are returned to the dispensary. Thus only fresh, protected, sterile drops are used in preparing an eye for operation. If further drops are needed after a patient reaches the operating theatre, the theatre technique already described is employed.

Post-Operative Drops.-These are issued individually and placed in the bedside drops cupboard (Fig. 5).

\section{Replacement of Drops}

Repeated bacteriological testing of drops that have been in use in the OutPatients Department and Casualty Ward has shown that they are still sterile and self-sterilizing after 3 months' use. This is perhaps as long as it is desirable to have such drops "in use", since there is a risk of evaporation with consequent concentration when the bottle is open. If bottles are kept closed, the contents would presumably be self-protecting indefinitely. As a routine, however, all drops are replaced at the end of one month.

\section{SPecial Problems}

In the course of this work the following problems arose and their solution may be of interest:

\section{Distilled Water}

Steam-heated stills should always have a pressure-control valve between them and the boiler to secure a uniform head of steam in working, and, with this steampressure operating, should be carefully adjusted. If these precautions are not observed such stills can be very wasteful and can deliver unsatisfactory distilled water. A further point is that they should be stripped, cleaned out, and examined from time to time, as they may rust through or become furred up, and are liable to develop cracks giving direct contamination between the cooling water and distilled water. The distilled water must be collected in a suitable container and this must be sterilized from time to time, preferably daily. The danger here is that, in cooling down, distilled water is very liable to contamination by Ps. pyocyanea, and once this infection is established a cumulative infection will occur unless the vessel is frequently sterilized.

If pyrogen-free water is required then a glass-lined still is necessary.

\section{Condensate Water}

Steam-condensate water is usually available in large quantities in the boiler house and, apart from pharmaceutical purposes, this is a satisfactory alternative to distilled water, e.g. for use in sterilizers, for washing out bottles, and so on. The problem of storing and conveying such water was solved by the use of 5-gallo 
milk churns, but if this is done it is necessary to have the churns tin-dipped, not galvanized, since galvanizing corrodes when autoclaved, and also to have the tindipped churn plated with tin internally to seal off the pores always present after "dipping"*.

\section{Saline}

An abundant supply of sterile saline at body temperature is very desirable throughout an eye hospital. The possibility of using standard aquarium thermostats for this purpose was first suggested at St. Thomas's Hospital and has been developed in the following way at Moorfields:

A standard fish tank is mounted on a standard angle-iron carrying-frame with one lower frame on which rests a plate-glass shelf. The manufacturers will supply this tank with an aluminium hinged lid as illustrated (Fig. 8 and Fig. 9, overleaf). $\dagger$ The lid should have a drip sill, otherwise condensed water will run outside the tank when the lid is raised. Heating is by two standard heaters placed on the floor of the aquarium underneath the Perspex shelf. This is carried on several Perspex pillars and is a safeguard against a dropped bottle going through the bottom of the tank while distributing the heated water. The

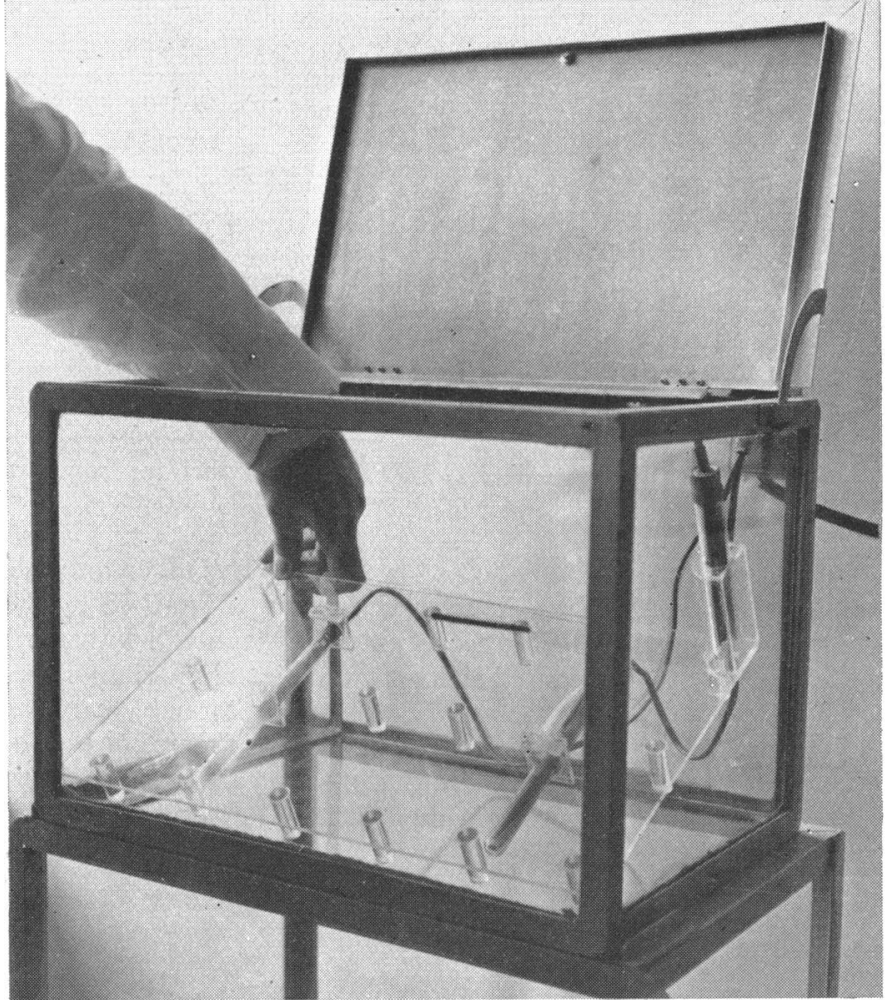

FIG. 8.-Saline tank with hinged lid for supplying saline at body temperature.

* Dairy Supply Co, Ltd, Cumberland Avenue, N.W.10.

† Supplier: Fishtanks Ltd., George Street, London, W.1. 


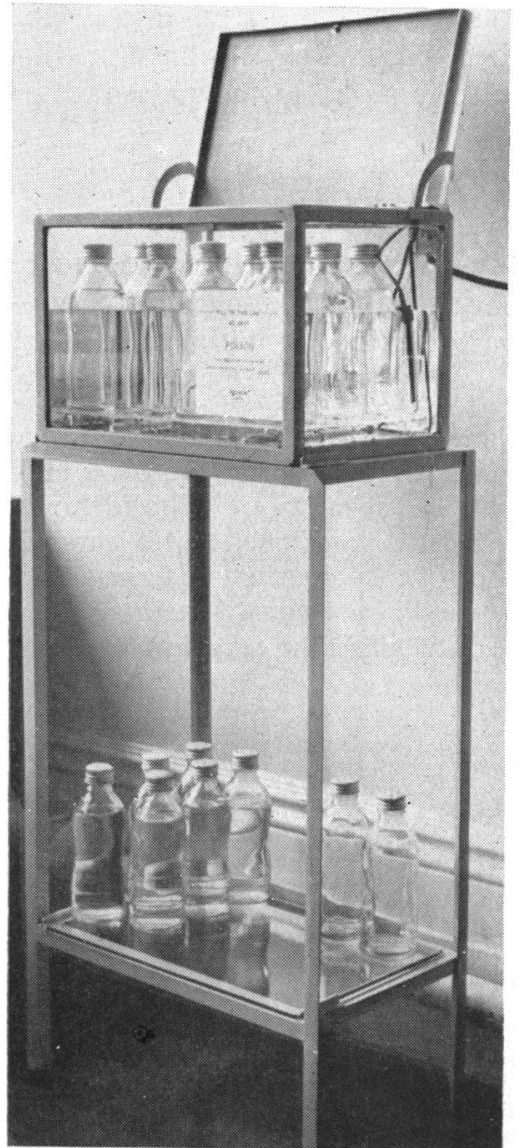

Fig. 9.--Saline tank in use with lower shelf for full or used bottles. thermostat is a standard aquarium thermostat set for just over blood heat, preferably $102^{\circ} \mathrm{F}$., protected by a Perspex shield, and in circuit with the heaters. The earth terminal is connected rigidly to the metal frame of the tank and to a stout copper strip running down inside the tank, which is bent to lie on the bottom (P.M.N. attacks solder). The tank itself contains 0.01 per cent. P.M.N. solution in distilled water. The level to which the tank should be filled is marked so that when there are eleven bottles in the tank it is comfortably-full. The level is made up with distilled water to this mark daily. The saline is put up in standard blood-bottles. Blood-bottles were adopted because they are of convenient size and are constructed with a waist so that they afford an easy non-slip grip to a small hand. Full and empty bottles are kept on the tray underneath, there being eleven full bottles in the tank at any one time. By starting the tank with the rear. left-hand space unoccupied and replacing a cold full bottle to the left of the space from which a

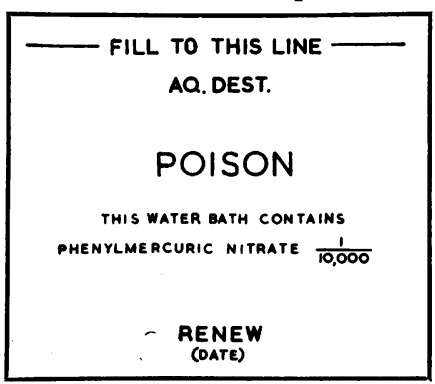

FIG. 10.-Label for saline tank showing renewal date.

warm full bottle has been taken, a fully-heated bottle is always taken and the tank always full. The caps for these bottles are of aluminium which is attacked by the mercury in the P.M.N. if a bottle is immersed. Plastic screw-caps which will withstand autoclaving are not, as yet, available in the required size. In practice aluminium caps have proved satisfactory, and are rarely wetted by the tank solution if reasonable care is taken. This P.M.N. solution is replaced once a month; the date wher replacement is due is written on a label attached to the tank (Fig. 10). Bottles of saline are taken out, dried off with a towel, and used for all normal purposes in the ward. They do not contain any preservative.

\section{Preparation of Saline}

For ophthalmic use 0.9 per cent. sodium chloride is stinging and contains a large excess of sodium and chlorine ions. It has been abandoned in favour of a Ringer solution equivalent to 0.6 per cent $\mathrm{NaCl}$ which is both physiological as regards ion distribution and comfortable to the patient. 
To prepare this, one tablet (B.D.H. 74A) is put into a washed blood-bottle, which is filled up to the mark with distilled water $(540 \mathrm{ml}$.), and the cap screwed on. Such bottles are put into a standard pint-bottle milk crate, and as many crates as may be necessary are prepared in this way and stacked one on top of the other. These are transposed to the major autoclave last thing in the day's work; they are brought up to $115^{\circ} \mathrm{C}$. when the pressure is turned off and the apparatus left to cool overnight. This is important if a certain amount of breakage and, where the caps are not tightly screwed down, boilingover are to be avoided. Using this procedure it is rare to encounter any trouble. The next morning the bottles are removed and carried in their crates to the various wards of the hospital.

\section{Anterior Chamber Washouts}

The provision of sterile physiological Ringer saline solution equivalent to 0.9 per cent. $\mathrm{NaCl}$ for anterior chamber washouts and for use in the theatre presented a considerable problem. Plastic screw-caps which will withstand autoclaving are available for 6-oz. bottles, and this size is convenient.

A solution is made by dissolving one tablet (B.D.H. 75B) in $540 \mathrm{ml}$. pyrogen-free distilled water, and the small bottles are filled. The cap is screwed down on to its rubber washer and the whole autoclaved as for saline for the wards. These bottles are totally immersed in 0.01 per cent. P.M.N. solution in a saline tank (Figs 8 and 9) in or near to the operating theatre. The tank as designed is flash-proof. The bottles can be removed from the tank at blood heat, and being sterile can be placed directly on to the operating trolley and dried off with a sterile towel. Any saline left at the end of the operation is discarded.

\section{Drops and Solutions for use in Conjunction with Contact Lenses}

Neither of the preservatives can be used in effective concentration under a contact lens, where they are intolerably uncomfortable. For use under the contact lens, sterile unprotected fluorescein $\mathbf{0 . 2}$ per cent. in 2 per cent. sodii. bicarb. and sodii. bicarb. 2 per cent. are required.

Pint bottles of these solutions are pasteurized: pathogenic bacteria are thus destroyed and the sodii. bicarb. is not broken down as it is by boiling. These lotions are transferred to sterile chloroform dropper-bottles, and are used for filling the individual contact lenses.

Liquid paraffin in quarter-ounce drop bottles is similarly pasteurized daily.

\section{Contact Lens Solution}

Sodii. bicarb. 2 per cent. has proved effective for this purpose. Contamination may be prevented by the inclusion of 0.2 per cent chlorbutol. Suitable tablets for this purpose are prepared by British Drug Houses (S. 74). This concentration of chlorbutol is adequate for the patient's use at home where there is no question of cross-infection. If the concentration of chlorbutol is increased it tends to separate out of solution in cold weather, producing needle-sharp crystals which are intolerable under a contact lens.

\section{Bacteriological Control}

From its inception the scheme has been under continuous bacteriological control. The senior surgeon has selected four or more bottles of drops or lotion in use anywhere in the hospital each month, and these have been tested at the Institute 
of Ophthalmology. Hitherto these tests, more than two hundred in all, have proved sterile. The measures adopted secure a high degree of protection under routine clinical conditions.

\section{SUMMARY}

The methods employed at Moorfields during the years 1955-1957 to secure sterile drops and eye lotions throughout the hospital are set out in detail, and the following essential points are noted:

(a) The use of screw-cap drop-bottles, securing freedom from evaporation and protection of the lip of the bottle.

(b) The use of an effective protective substance in all drops.

(c) The devising of a system of bottle sterilization, filling, and labelling, which has enabled the scheme to be put into operation without greatly increasing the staff in the dispensary (some 10 per cent. in salaries).

(d) The use of a system of labels to identify by colour the essential characteristics of drops dispensed and to present the necessary information simply so that only one label need be applied to any bottle whatever its destination may be.

(e) The establishment of special arrangements in the Out-Patients Department and Casualty Ward, and the use in the wards of specially designed dropbottle cabinets for individual drops.

The use of a common bottle of drops for the treatment of successive patients in a ward is strongly deprecated. A simple technique securing the sterility of drops used in the operating theatre has been worked out, as has a method for the preoperative preparation of patients.

$(f)$ The provision of sterile Ringer-saline lotion (equivalent to 0.6 per cent $\mathrm{NaCl}$ ) at blood heat throughout the hospital. A method of preparing and presenting sterile Ringer-saline solution (equivalent 0.9 per cent. $\mathrm{NaCl}$ ) at blood heat for anterior chamber washouts and theatre use is described.

$(g)$ The provision of adequate protection for lotions used in the special conditions of the Contact Lens Department.

Routine tests for sterility have shown that the measures adopted secure a high degree of protection under clinical conditions.

A scheme of this magnitude involving big changes in method in many departments of the hospital could not have been carried through without the keen support and continued criticism and advice of the Dispensary and Sterilization Committee under the Chairmanship of Prof. Norman Ashton, to whom whatever success may have been achieved must be attributed. Thanks are due also to Dr. Peter Hansell, Medical Illustration Department, Institute of Ophthalmology, for kindly preparing the illustrations. It is a pleasure to acknowledge the helpfulness of the senior members of the commercial firms named in this paper, all of whom have given much time and thought to the adaptation of their particular products to this purpose.

\section{REFERENCES}

International Federation of Ophthalmological Societies (1954). Brit. J. Ophthal., 38, 767. KLeIN, M., and Millwood, E. G. (1955). Trans. ophthal. Soc. U.K., 75, 515. - and Walther, W. W. (1954). J. Pharm. Pharmacol., 6, 725.

RIDley, F. (1931). Proc. roy. Soc. Med., 25, 480. 